\title{
High pressure chronic retention: a life-threatening clinical entity
}

\section{SAS Goonewardena ${ }^{1}$ and S Sivapriyan ${ }^{2}$}

(Index words: Diuresis, hypertension, nocturnal enuresis, women patients with high pressure chronic retention)

\begin{abstract}
Objectives To report our experience with high pressure chronic retention (HPCR), a clinical syndrome with potentially disastrous consequences.
\end{abstract}

Design A prospective hospital based descriptive study.

Setting A urology unit at the National Hospital of Sri Lanka, Colombo.

Patients Forty seven consecutive new patients with HPCR evaluated during a 2-year period.

Results Of the 47 (39 male) patients, 15 (32\%) were below 50 years of age. Nocturnal enuresis was encountered in $32(68 \%)$ patients, and a tense, non-tender distended bladder found in all 47 patients. Hypertension was recorded in $25.5 \%$ of the patients. Bilateral hydroureteronephrosis was detected on ultrasonography in nearly $80 \%$ of the patients, and renal impairment was found in 20 (42.5\%). The mean retained volume was $968 \mathrm{~mL}$. Seven (15\%) patients developed post-obstructive diuresis.

Eight women (mean age 47.5 years, range $30-70$ years) had HPCR. Four had no obvious cause. Six (75\%) had adult onset nocturnal enuresis. Renal impairment was found in four $(50 \%)$ patients. Post-obstructive diuresis was recorded in two women.

Conclusions HPCR, a clinical entity known to affect the elderly in the West, was found to affect a relatively young patient group in Sri Lanka. The symptom of adult-onset nocturnal enuresis should alert the clinician to the possibility of HPCR. Renal failure is common at initial presentation. Urethral catheterization could lead to lifeendangering diuresis. We describe eight women with this entity, hitherto unreported in the medical literature.

\section{Introduction}

Chronic urinary retention has been arbitrarily defined as the situation in which the volume of residual urine in the bladder after a normal void exceeds $300 \mathrm{~mL}$ [1]. High pressure chronic retention (HPCR), a distinct entity of chronic urinary retention, is characterised by four criteria: (i) late onset enuresis, (ii) a tense painless palpable bladder, (iii) hypertension, and (iv) bilateral hydronephrosis with hydroureter, often leading to uraemia and death [2]. The symptom of late onset enuresis is typically a small leakage (10-20 mL) occurring soon after falling asleep, the patient invariably being awakened immediately by the feeling of dampness. The leakage never occurs when the patient is awake [2]. The dangers of delay in the diagnosis and treatment of HPCR have been known for some years [3]. We report our experience in a consecutive group of patients with HPCR.

\section{Patients and methods}

Forty seven consecutive patients (39 males, mean age 56.3 years, SD 17.1, range 14-85 years), with HPCR treated at our unit between 1 February 1999 and 31 January 2001 were studied prospectively. Once the condition was suspected (by the detection of a tense painless palpable bladder) a urine culture, full blood count, serum creatinine, urea and electrolyte estimation were arranged. Abdominal ultrasonography was performed to confirm the diagnosis and define the presence or absence of bilateral upper urinary tract dilatation. A similar number of patients with indwelling urethral or suprapubic catheters even with a strong suspicion of HPCR were excluded from the study. Patients with daytime and nocturnal incontinence too were excluded from the study. Serum creatinine value of $>132.6 \mu \mathrm{mol} / \mathrm{L}$ was considered as renal impairment. A patient was deemed hypertensive when the supine diastolic blood pressure was persistently over 90-95 $\mathrm{mmHg}$.

The cause of HPCR was ascertained. Patients whose blood urea was $15 \mathrm{mmol} / \mathrm{L}$ or above were catheterized soon after voiding and the post-void residual urine volume (PVRV) recorded. Furthermore, an hourly urine output chart was maintained to detect post-obstructive diuresis (defined as the passage of more than $200 \mathrm{~mL}$ urine / $\mathrm{h}$ for 24 hours or more after bladder decompression). Those with blood urea less than $15 \mathrm{mmol} / \mathrm{L}$ had definitive surgery performed on a priority basis and had PVRV estimation at cystoscopy. Definitive treatment was undertaken at some stage in all patients, after stabilisation of renal function in chronic renal failure (CRF) patients. Analysis of the type of surgical treatment and the treatment outcome was deemed beyond the scope of this study. There were no perioperative deaths in this series.

\section{Results}

Thirty nine males (mean age 58, SD 17.3, range 14-85 years) and eight women (mean age 47.5, SD 13.5, range

${ }^{1}$ Urological Surgeon, 2 Senior House Officer, Department of Urology, National Hospital of Sri Lanka, Colombo. Correspondence: SASG, e-mail: <sasgurol@sltnet.lk> (Competing interests: none declared). Received 5 December 2003 and accepted 15 March 2004. 
30-70 years) with HPCR were studied during the 2-year period.

There were 10 males below 50 years of age (of whom three were 20 years or below) and five women under 50 years of age.

The aetiology of HPCR in the two sexes and the incidence of renal impairment are shown in Table 1. Nocturnal enuresis (late onset enuresis) was noted in 26 $(66.6 \%)$ males and six (75\%) women. On clinical examination, all 47 patients were found to have a tense painless palpable bladder. Hypertension was found in 12 patients (nine men) on initial presentation.

Ultrasonography was performed in 44 patients, of whom $35(79.5 \%)$ had bilateral hydroureteronephrosis. Out of 47 patients, 14 had three and 10 had all the criteria ( $51.1 \%$ of the patients had three or more of these criteria). In $20(42.5 \%)$ patients the serum creatinine levels were raised $(150.3-1281.8 \mu \mathrm{mol} / \mathrm{L})$. Seventeen $(43.6 \%)$ men and four $(50 \%)$ women had an elevated serum creatinine. The mean retained (residual) volume after initial catheterization or at cystoscopy was $968 \mathrm{~mL}$ (range 400-2300 mL). Seven $(14.9 \%)$ patients developed post-obstructive diuresis (range 4.8-9 litres daily). In five patients (three men) with post-obstructive diuresis, the serum creatinine and urea levels were normal.

One man who produced 9 litres of urine in the first 24 hours post-catheterization too had a serum creatinine level within normal limits $(123.8 \mu \mathrm{mol} / \mathrm{L})$.

HPCR has not been documented in females in the medical literature. Table 2 outlines relevant details of the eight female patients.

\section{Discussion}

HPCR is an entity about which there are few published data and many as yet unanswered queries. There is no question what HPCR is. Although many patients present to urologists with the highly specific symptom of late onset enuresis (nocturnal enuresis), a sizeable minority are referred to medical clinics by their general practitioners because of the associated features of a raised blood urea or serum creatinine, congestive cardiac failure, and hypertension that does not respond to treatment [5]. The dangers of mismanagement of HPCR include uraemic death and hypovolaemic circulatory collapse from neglected post-obstructive diuresis [3].

This study describes the clinical characteristics of 47 patients, managed over a 2 -year period, with a mean age of 56 years, a relatively young patient population. Since the term "high pressure chronic retention" (HPCR) was coined in 1983 to describe this syndrome, the condition had been exclusively reported in men [2]. We report HPCR in eight females, with associated bilateral hydroureteronephrosis and uraemia in six and four women, respectively. However, an identifiable cause for HPCR could be established only in four women. Lack of facilities for urodynamic evaluation in these women were deemed a considerable drawback. Urologists from Manchester, who originally described this condition, stated that they do not know whether the condition occurs in women or whether it cannot progress owing to the relative inability of the female sphincter mechanism to withstand high intravesical pressures [2]. In the present series, we had five women with no demonstrable mechanical obstruction to the bladder outlet, thereby refuting the aforementioned claims convincingly.

The majority of men in this study had benign prostatic obstruction. Cancer of the prostate was found only in $12.8 \%$ of men. Studies from Britain have reported a high incidence of malignant disease of the prostate (24-39\%) in HPCR patients $[3,4]$.

The classical symptom of late onset enuresis was found in two thirds of our patients, similar to the series from Newcastle [4]. On clinical examination, all patients

Table 1. Aetiology of high pressure chronic retention and the incidence of renal impairment (CRF)

\begin{tabular}{|c|c|c|c|c|c|c|c|}
\hline \multicolumn{4}{|c|}{ Male } & \multicolumn{4}{|c|}{ Female } \\
\hline Cause & No. & $(\%)$ & $C R F$ & Cause & No. & $(\%)$ & $C R F$ \\
\hline Benign prostatic & & & & Urethral stenosis & 1 & $(12.5)$ & 1 \\
\hline hyperplasia & 21 & $(53.8)$ & 8 & Urethral caruncle & 1 & $(12.5)$ & - \\
\hline Prostate cancer & 5 & $(12.8)$ & 2 & Diabetic cystopathy & 1 & $(12.5)$ & - \\
\hline \multicolumn{8}{|l|}{ Granulomatous } \\
\hline Prostatitis & 1 & $(2.6)$ & 1 & & & & \\
\hline Urethral stricture & 4 & $(10.3)$ & 1 & & & & \\
\hline Neuropathic bladder & 2 & $(5.1)$ & 1 & & & & \\
\hline \multicolumn{8}{|l|}{ Congenital bladder } \\
\hline Neck obstruction & 2 & $(5.1)$ & 2 & & & & \\
\hline Bladder neck hypertrophy & 1 & $(2.6)$ & - & & & & \\
\hline Undetermined & 3 & $(7.7)$ & 2 & Undetermined & 5 & $(62.5)$ & 2 \\
\hline Total & 39 & $(100)$ & 17 & Total & 8 & $(100)$ & 3 \\
\hline
\end{tabular}

CRF-chronic renal failure 
Table 2. Characteristics of eight women with HPCR

\begin{tabular}{|c|c|c|c|c|c|c|c|c|c|}
\hline No. & Age & $\begin{array}{c}\text { Presenting } \\
\text { Symptom } \\
\text { (duration) }\end{array}$ & $N E$ & $\begin{array}{c}\text { Systemic } \\
B P\end{array}$ & $H U N$ & $S C r$ & $\begin{array}{c}\text { Retained } \\
\text { volume } \\
(m L)\end{array}$ & $\begin{array}{l}P O D \\
(m L)\end{array}$ & Cause \\
\hline 1 & 47 & $\begin{array}{l}\text { poor stream } \\
(2 \text { months })\end{array}$ & + & $180 / 120$ & + & 1034.3 & 2300 & $\begin{array}{c}+ \\
6000\end{array}$ & $\begin{array}{l}\text { Urethral } \\
\text { stenosis }\end{array}$ \\
\hline 2 & 70 & $\begin{array}{l}\text { poor stream } \\
(6 \text { months })\end{array}$ & - & $180 / 100$ & + & 512.8 & 1000 & - & Undetermined \\
\hline 3 & 32 & $\begin{array}{c}\text { NE } \\
(10 \text { weeks) }\end{array}$ & + & $130 / 70$ & + & 221.0 & 900 & - & Undetermined \\
\hline 4 & 47 & $\begin{array}{l}\text { poor stream } \\
(2 \text { years })\end{array}$ & + & $130 / 90$ & + & 61.9 & 1000 & - & Undetermined \\
\hline 5 & 62 & $\begin{array}{l}\text { poor stream } \\
(2 \text { months })\end{array}$ & - & $130 / 80$ & + & 123.8 & 750 & - & $\begin{array}{l}\text { Urethral } \\
\text { stenosis }\end{array}$ \\
\hline 6 & 40 & $\begin{array}{l}\text { abd. distension } \\
\quad(2 \text { months })\end{array}$ & + & $130 / 80$ & + & 61.9 & 950 & $\begin{array}{c}+ \\
5800\end{array}$ & $\begin{array}{l}\text { Diabetic } \\
\text { cystopathy }\end{array}$ \\
\hline 7 & 30 & $\begin{array}{c}\text { NE } \\
\text { (4 months) }\end{array}$ & + & $120 / 70$ & - & 79.6 & 500 & - & $\begin{array}{l}\text { Urethral } \\
\text { caruncle }\end{array}$ \\
\hline 8 & 52 & $\begin{array}{c}\mathrm{NE} \\
\text { (1 month) }\end{array}$ & + & $210 / 95$ & - & 176.8 & 400 & - & Undetermined \\
\hline
\end{tabular}

All patients had tense, painless palpable bladders

HUN-Hydroureteronephrosis, NE-Nocturnal enuresis, POD-Post-obstructive diuresis, Scr-serum creatinine ( $\mu$ mol/L), '+' present, '-' absent

were found to have a tense, non-tender, palpable bladder, a universally reported physical sign in all previous studies [2-4]. In the present series, hypertension was found only in $12(25.5 \%)$ patients at the time of initial presentation. One study found hypertension in 52\% of HPCR patients before bladder drainage and achieved blood pressure reduction in all the hypertensive patients following bladder drainage [5]. Significant bilateral hydroureteronephrosis was encountered in nearly $80 \%$ of patients on ultrasonography, similar to the findings from other published series $[2,3]$. Raised serum creatinine levels were observed only in $42.5 \%$ of our patients, a much lower incidence than previously reported [2-4]. Mean retained volume of 968 $\mathrm{mL}$ in our patients was comparatively low [2-4]. Fifteen per cent of patients developed post-obstructive diuresis after bladder decompression. In contrast, a British study reported $78 \%$ of the patients having post-obstructive diuresis [3]. In a few cases, a mismanaged or missed postobstructive diuresis, even in non-uraemic patients, may lead to hypovolaemia and circulatory collapse [3]. Urethral catheterization should never be performed on an out-patient basis since these patients require close monitoring of the urine output and serum electrolytes post-catheterization.

To summarise, HPCR is a serious condition that requires prompt diagnosis and appropriate management, preferably in a urological unit. Adult onset nocturnal enuresis should raise a high index of suspicion and abdominal examination clinches the diagnosis clinically. Urethral catheterization and sending the patient home, a common practice in Sri Lanka, could be a recipe for disaster in these patients.

\section{References}

1. Jones DA, George NJ. Interactive obstructive uropathy in man. British Journal of Urology 1992; 69: 337-45.

2. George NJR, O'Reilly PH, Barnard RJ, Blacklock NJ. High pressure chronic retention. British Medical Journal 1983; 286: 1780-3.

3. O'Reilly PH, Brooman PJ, Farrah NB, Mason GC. High pressure chronic retention: incidence, aetiology and sinister implications. British Journal of Urology 1986; 58: 644-6.

4. Styles RA, Ramsden PD, Neal DE. Chronic retention of urine: the relationship between upper tract dilatation and bladder pressure. British Journal of Urology 1986; 58: 647-51.

5. Jones DA, O'Reilly PH, George NJR, Barnard RJ. Reversible hypertension associated with unrecognized high pressure chronic retention of urine. Lancet 1987; 329: 1052-4. 